\title{
An Increase in Ethylene Sensitivity Is Associated with Jasmonate-Promoted Senescence of Detached Rice Leaves
}

\author{
F.-Y. Tsai, K. T. Hung, and C. H. Kao \\ Department of Agronomy, National Taiwan University, Taipei, Taiwan, Republic of China
}

Received March 11, 1996; accepted October 24, 1996

\begin{abstract}
The role of ethylene in jasmonate-promoted senescence of detached rice leaves was investigated. Ethylene production in methyl jasmonate-treated leaf segments of rice was lower than in the control leaves. Treatment of leaf segments with silver nitrate or/and silver thiosulfate, inhibitors of ethylene action, inhibited methyl jasmonate-, jasmonic acid-, linolenic acid-, and abscisic acid-promoted senescence of detached leaves. We suggest that an increase in ethylene sensitivity, but not ethylene level, is the initial event triggering the enhanced senescence by jasmonates of detached rice leaves.
\end{abstract}

Key Words. Ethylene-Jasmonates-Oryza sativaSenescene

Jasmonic acid (JA) and its methyl ester, methyl jasmonate (MJ), are naturally occurring growth regulators found in higher plants (Meyer et al. 1984, Sembdner and Parthier 1993). Jasmonates have been shown to be powerful promoters of leaf senescence (Chou and Kao 1992, Cuello et al. 1990, Sembdner and Parthier 1993, Ueda and Kato 1981, Weidhase et al. 1987). However, the mechanism whereby jasmonates promote leaf senescence remains unclear. Ethylene was found to play a significant role in promoting senescence of leaves (Mattoo and Aharoni 1988). Using cucumber cotyledons, Abeles et al. (1989) found that MJ was as effective as ethylene in inducing senescence. In addition to this observation, silver thiosulfate (STS) had no effect on the ability of MJ to promote senescence. Based on these results they suggested that the action of MJ was inde-

Abbreviations: JA, jasmonic acid; MJ, methyl jasmonate; STS, silver thiosulfate; ABA, abscisic acid.

* Author for correspondence. pendent of ethylene. Cuello et al. (1990) also reported that $\mathrm{MJ}$ and ethylene had different mechanisms in promoting the senescence of detached barley leaves. In this study the possible involvement of ethylene in the regulation of jasmonate-promoted senescence of detached rice leaves was investigated.

\section{Materials and Methods}

Rice (Oryza sativa L. cv. Taichung Native 1) was cultured as described previously (Kao 1980). The apical 3-cm segments excised from the third leaves of 12-day-old seedlings were used. A group of 10 segments was floated in a Petri dish containing $10 \mathrm{~mL}$ of test solutions. Incubation was carried out at $27^{\circ} \mathrm{C}$ in darkness.

Chlorophyll was determined according to Wintermans and De Mots (1965) after extraction in 96\% (v/v) ethanol. For protein extraction, leaf segments were homogenized in $50 \mathrm{~mm}$ sodium phosphate buffer $(\mathrm{pH}$ 6.8). The extracts were centrifugated at $17,600 \times g$ for $20 \mathrm{~min}$, and the supernatants were used for determination of protein by the method of Bradford (1976).

For determination of ethylene, leaf segments were placed vertically in test tubes that were plugged with rubber stoppers and incubated in darkness at $27^{\circ} \mathrm{C}$ for $1 \mathrm{~h}$. The ethylene in the gas phase of the plugged tubes was determined by analysis of a $1-\mathrm{mL}$ sample withdrawn with a hypodermic syringe as described elsewhere (Kao and Yang 1983).

In experiments with $\mathrm{Ag}^{+}$treatments, leaf segments were pretreated with $10 \mathrm{mg} / \mathrm{mL}$ silver nitrate for $30 \mathrm{~min}$ and then transferred to a Petri dish containing test solution. When STS was used as a source of $\mathrm{Ag}^{+}$, leaf segments were treated with STS and test solution. A stock solution of STS was prepared by mixing equal volumes of $0.01 \mathrm{M} \mathrm{AgNO}_{3}$ and $0.04 \mathrm{M} \mathrm{Na}_{2} \mathrm{~S}_{2} \mathrm{O}_{3}$ (Liu et al. 1990).

All experiments were repeated at least twice. Data are presented as the results of a single experiment typical of the trends seen in the repeated experiments.

\section{Results and Discussion}

The senescence of detached rice leaves was followed by measuring the decrease of chlorophyll and protein. Fig. 1 shows the time courses of protein and chlorophyll levels of detached rice leaves floating on water or MJ $(45 \mu \mathrm{M})$ in the dark. It is clear that the MJ significantly promotes 

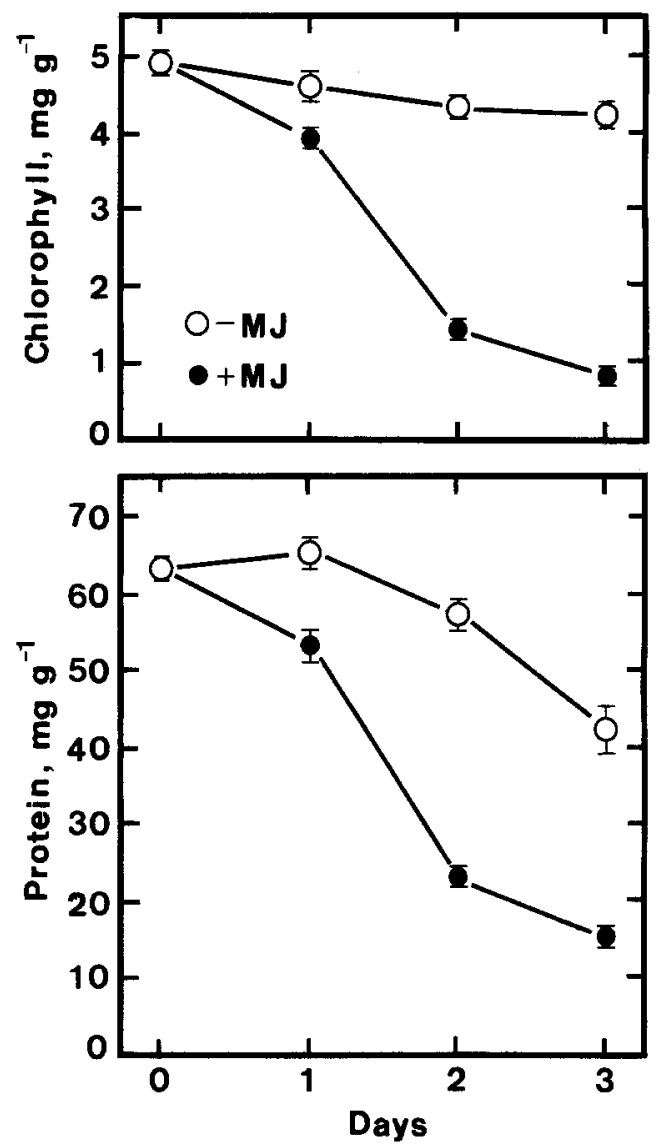

Fig. 1. Time course of chlorophyll and protein levels in detached rice leaves floating on water or MJ $(45 \mu \mathrm{M})$ in darkness. Bars indicate S.E. $(n=4)$.

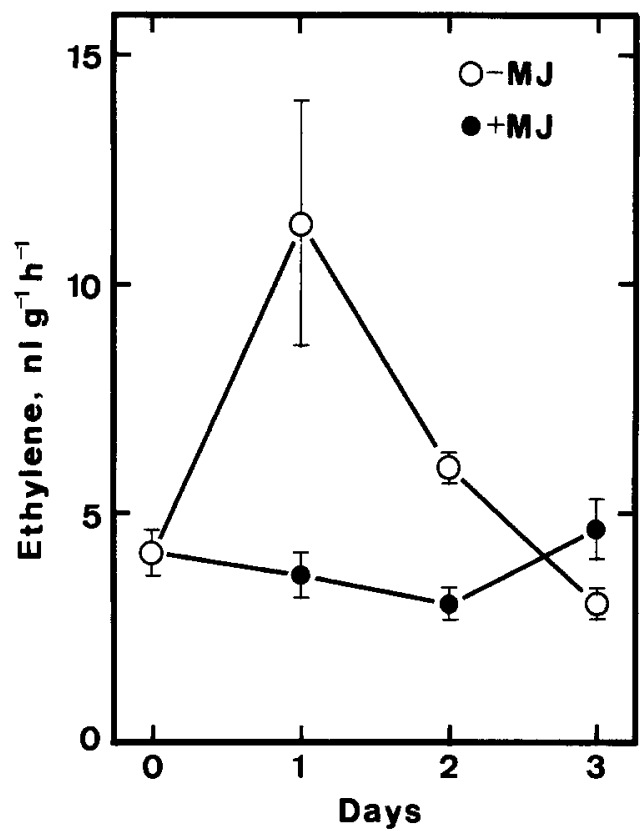

Fig. 2. Time course of ethylene production in detached rice leaves floating on water or MJ $(45 \mu \mathrm{M})$ in darkness. Bars indicate S.E. $(n=4)$.

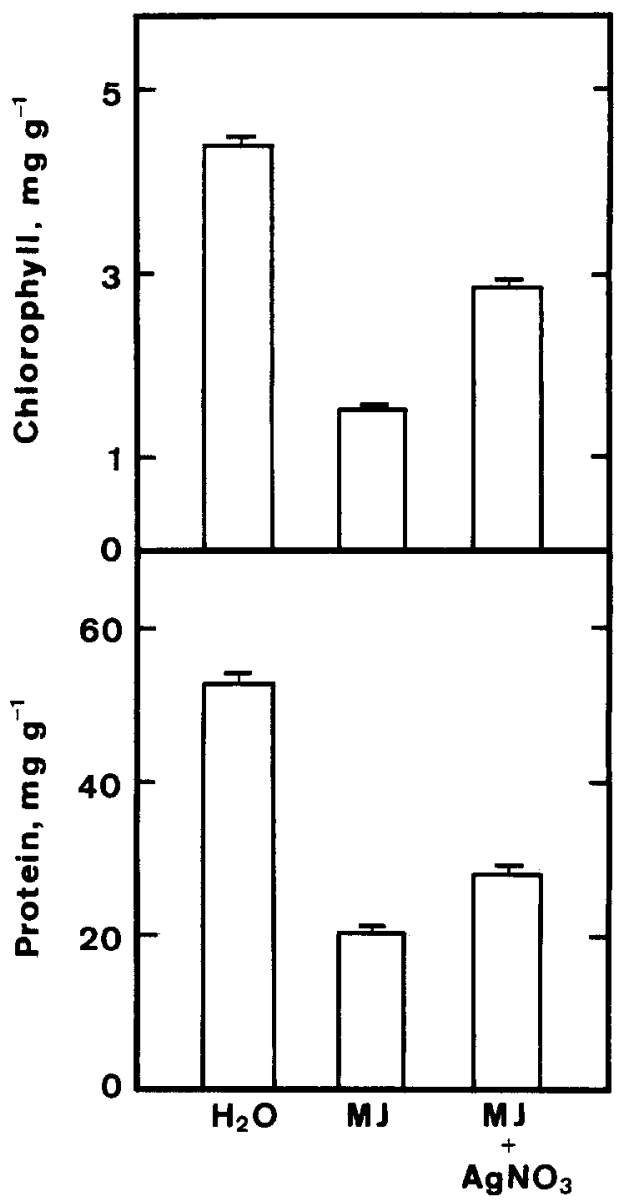

Fig. 3. Effect of silver nitrate pretreatment on the MJ-promoted senescence of detached rice leaves. Leaf segments were pretreated with silver nitrate $(10 \mathrm{mg} / \mathrm{mL})$ for $30 \mathrm{~min}$ in darkness and then transferred to distilled water or MJ $(45 \mu \mathrm{M})$ for 3 days. Bars indicate S.E. $(n=4)$.

the senescence of detached rice leaves. These results are in agreement with earlier reports of other investigators (Chou and Kao 1992, Cuello et al. 1990, Ueda and Kato 1981, Weidhase et al. 1987).

Ethylene production in water-treated leaf segments increased significantly during the first $24 \mathrm{~h}$ and decreased subsequently (Fig. 2). This result is consistent with our early finding that ethylene production precedes the senescence of detached rice leaves (Kao and Yang 1983), indicating that ethylene production participates in the regulation of rice leaf senescence. If MJ-promoted senescence of detached rice leaves is mediated through ethylene production, then ethylene production in MJtreated leaf segments is expected to be higher than that in water-treated leaf segments. However, as indicated in Fig. 2, this does not seem to be the case.

If a change in ethylene production is excluded as an explanation for the MJ-promoted senescence of detached rice leaves, a change in sensitivity to ethylene is an alternate possibility. This possibility was tested by using 


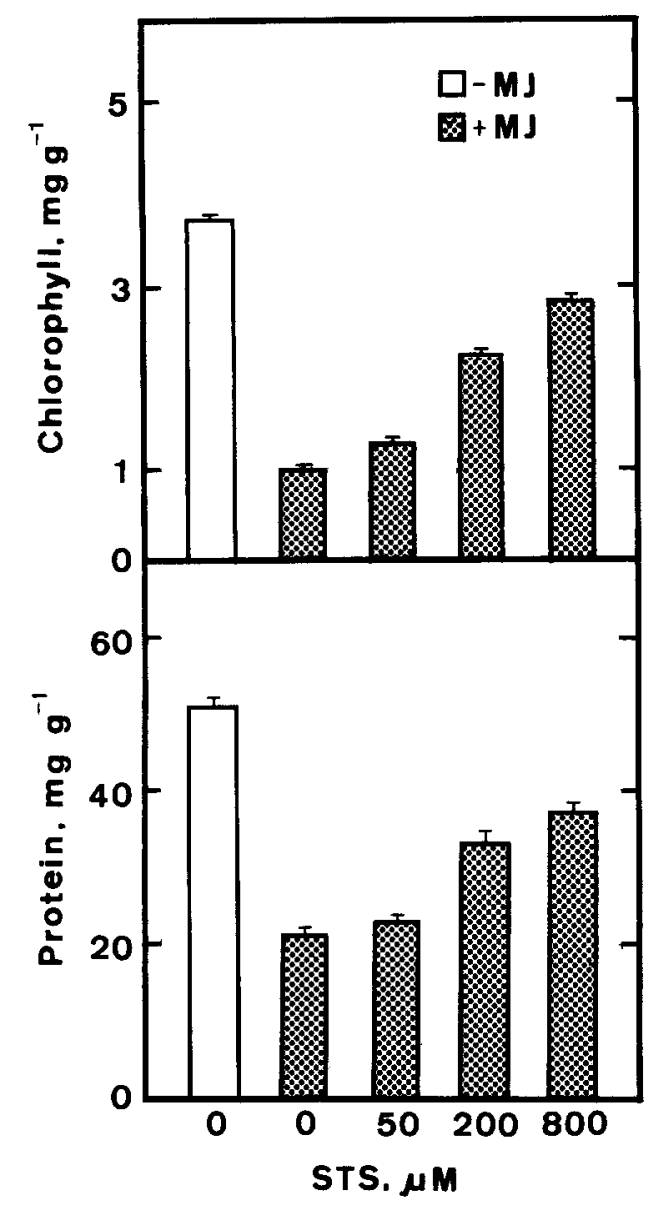

Fig. 4. Effect of STS on the MJ-promoted senescence of detached rice leaves. The concentration of MJ was $55 \mu \mathrm{M}$. Chlorophyll and protein levels were determined after 3 days in darkness. Bars indicate S.E. ( $n$ $=4$ ).

the inhibitor of ethylene action, $\mathrm{Ag}^{+}$(Beyer 1976). Leaf segments were pretreated with silver nitrate for $30 \mathrm{~min}$ and then transferred to distilled water or $\mathrm{MJ}$ for 3 days in the dark. As indicated in Fig. 3, silver nitrate pretreatment resulted in an inhibition of MJ-promoted senescence of detached rice leaves. Toxic effects of silver nitrate have been reported (Lis et al. 1984, Liu et al. 1990). The advantages of using STS have been described by others and are related to lower free $\mathrm{Ag}^{+}$in STS solutions and a lower phytotoxicity of this compound (Liu et al. 1990). Thus, a change in ethylene sensitivity in MJ-treated leaf segments was tested further by using STS. STS was also found to be effective in inhibiting MJ-promoted senescence of detached rice leaves Fig. 4).

JA was also observed to be effective, although to a lesser extent, in promoting the senescence of detached rice leaves (Fig. 5). Similar to MJ, the response of JA was also inhibited by STS (Fig. 5).

Linolenic acid (18:3) is known to be the precursor in the proposed biosynthetic pathway of JA (Sembdner and Parthier 1993) and has been shown to be a senescence-

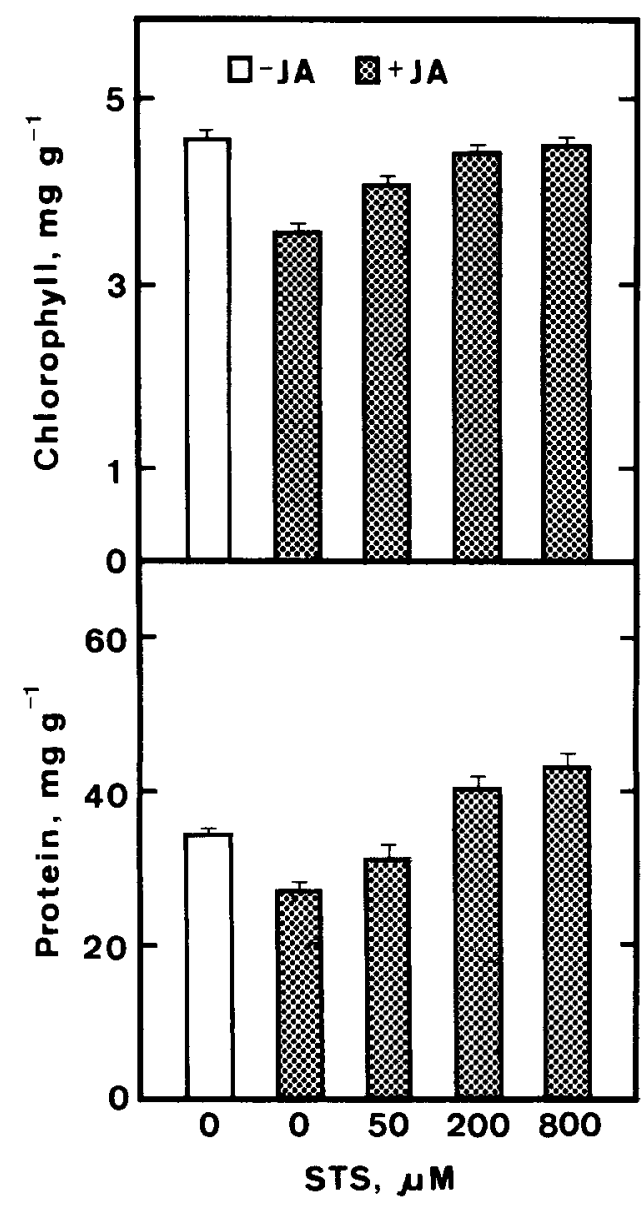

Fig. 5. Effect of STS on the JA-promoted senescence of detached rice leaves. The concentration of JA was $45 \mu \mathrm{M}$. Chlorophyll and protein levels were determined after 3 days in darkness. Bars indicate S.E. ( $n$ $=4$ ).

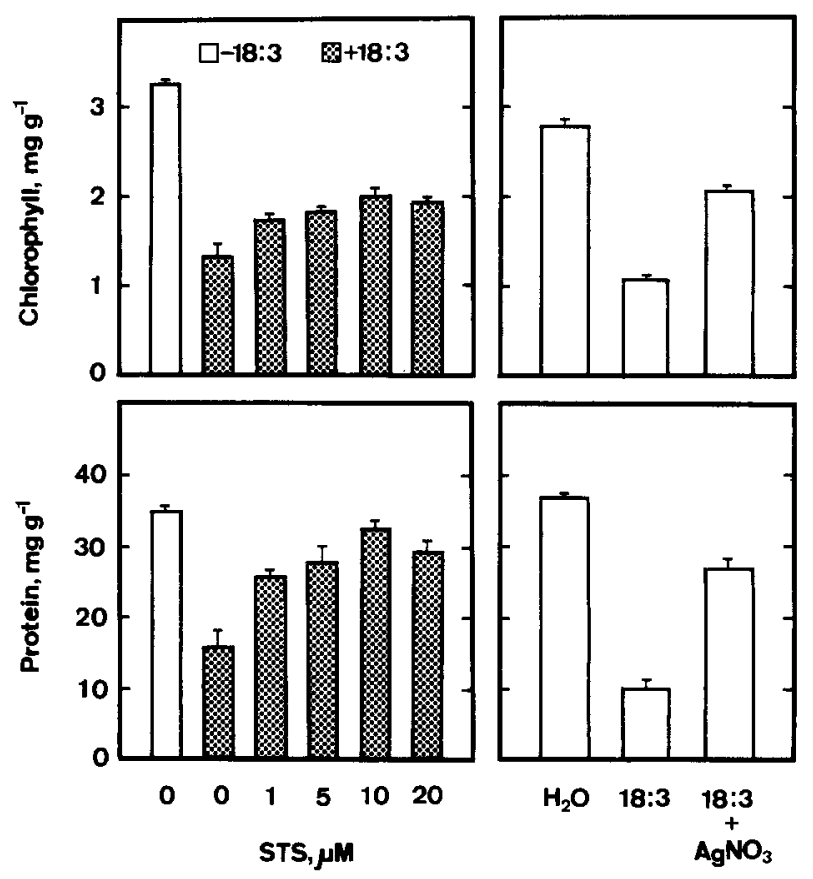

Fig. 6. Effect of STS and silver nitrate on linolenic acid-promoted senescence of detached rice leaves. Linolenic acid $(18: 3,5 \mathrm{~mm})$ was dissolved in $0.1 \%$ Tween 20 . Water treatment included $0.1 \%$ Tween 20. For silver nitrate experiments, leaf segments were pretreated with silver nitrate $(10 \mathrm{mg} / \mathrm{mL})$ for $30 \mathrm{~min}$ in darkness. Chlorophyll and protein levels were determined after 3 days in darkness. Bars indicate S.E. $(n=4)$. 


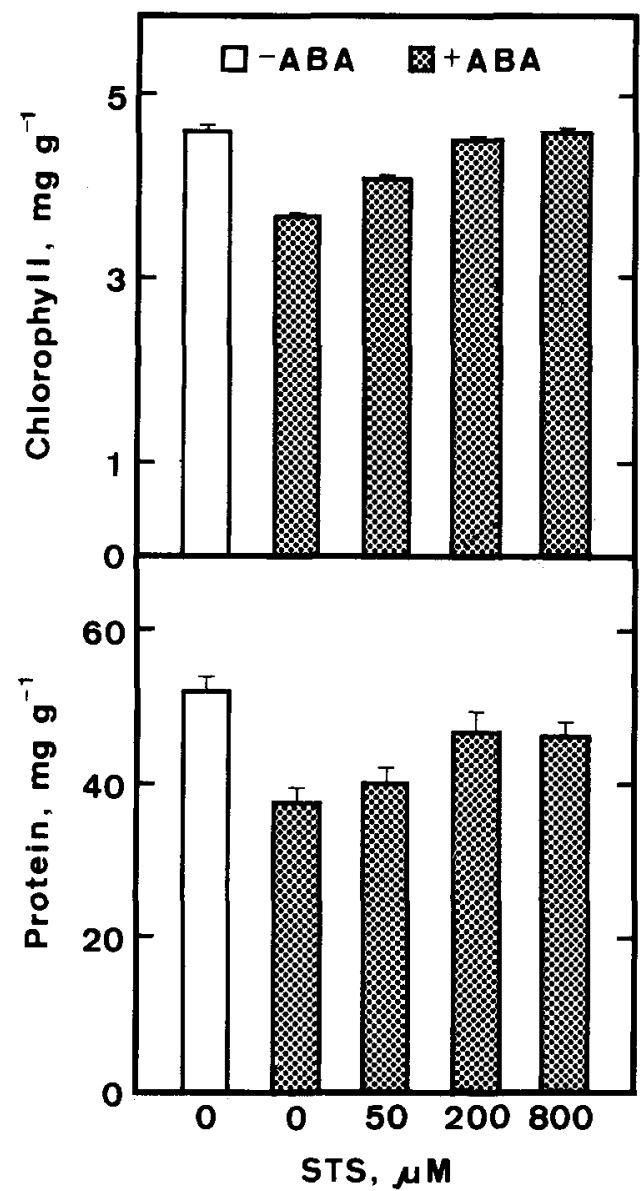

Fig. 7. Effect of STS on ABA-promoted senescence of detached rice leaves. The concentration of $\mathrm{ABA}$ was $45 \mu \mathrm{M}$. Chlorophyll and protein levels were determined after 3 days in darkness. Bars indicate S.E. ( $n$ $=4$ ).

promoting substance (Ueda and Kato 1982). Our unpublished data also show that the promotive effect of linolenic acid on the senescence of detached rice leaves may be the result of an effect of JA. Thus, it is of great interest to know whether the promotive response of linolenic acid on the senescence of detached rice leaves is mediated through a change in ethylene sensitivity. As indicated in Fig. 6, linolenic acid indeed changes the sensitivity of ethylene, as judged by the effect of silver nitrate and STS.

In our earlier work we found that $\mathrm{ABA}$ promoted the senescence of detached rice leaves but inhibited ethylene production (Kao and Yang 1983). We proposed, but did not prove, that $\mathrm{ABA}$ increases tissue sensitivity to ethylene. Since jasmonates and ABA have both chemical and physiological similarity (Anderson et al. 1989), we investigated the effect of STS on ABA-promoted senescence of detached rice leaves. The results in Fig. 7 indicate that our early proposal appears to be correct.

Although it has been shown that the action of JAs was independent of ethylene in other cases (Abeles et al. 1989, Cuello et al. 1990), our results strongly support the notion that ethylene plays a regulatory role in the JApromoted senescence of detached rice leaves. It is ethylene sensitivity rather than ethylene level which JAs affect during the course of the senescence of detached rice leaves.

Acknowledgments. This work was supported by National Science Council of Republic of China Grant (NSC 85-2321-B002-091). This paper is part 24 of the series Senescence of Rice Leaves.

\section{References}

Abeles FB, Hershberg L, Dunn LL (1989) Hormonal regulation and intracellular localization of a 33-kDa cationic peroxidase in excised cucumber cotyledons. Plant Physiol 89:664-668

Anderson JM, Spilatro SR, Klauer SF, Franceschi VR (1989) Jasmonic acid-dependent increase in the level of vegetative storage proteins in soybean. Plant Sci 62:45-52

Beyer EM Jr (1976) A potent inhibitor of ethylene action in plants. Plant Physiol 58:268-271

Bradford MM (1976) A rapid and sensitive method for the quantitation of microgram quantities of protein utilizing the principle of protein-dye binding. Anal Biochem 72:248-254

Chou CM, Kao CH (1992) Methyl jasmonate, calcium, and leaf senescence in rice. Plant Physiol 99:1693-1694

Cuello J, Quiles MJ, Garcia C, Sabater B (1990) Effect of light and growth substances on senescence of barley leaf segments at different developmental stages. Bot Bull Acad Sin 31:107-112

Kao CH (1980) Senescence of rice leaves. IV. Influence of benzyladenine on chlorophyll degradation. Plant Cell Physiol 21:12551262

Kao CH, Yang SF (1983) Role of ethylene in the senescence of detached rice leaves. Plant Physiol 73:881-885

Lis KK, Kwakkenbos AAM, Veen H (1984) Differential effects of silver salts in apple tissue. Plant Sci Lett 33:1-6

Liu J, Mukherjee I, Reid DM (1990) Adventitious rooting in hypocotyls of sunflower (Helianthus annus L.) seedlings. III. The role of ethylene. Physiol Plant 78:268-276

Mattoo AK, Aharoni N (1988) Ethylene and plant senescence. In: Nooden LD, Leopold AC (eds) Senescence and aging in plants. Academic Press, San Diego, pp 242-280

Meyer A, Mierch C, Buttner C, Dathe W, Sembdner G (1984) Occurrence of the plant growth regulator jasmonic acid in plants. $J$ Plant Growth Regul 3:1-8

Sembdner G, Parthier B (1993) The biochemistry and physiological and molecular actions of jasmonates. Annu Rev Plant Physiol Plant Mol Biol 44:569-589

Ueda J, Kato J (1981) Promotive effect of methyl jasmonate on oat leaf senescence in the light. Z Pflanzenphysiol 103:357-359

Ueda J, Kato J (1982) Abscisic acid and $C_{18}$-unsaturated fatty acids as senescence-promoting substances from oat plants. J Plant Growth Regul 1:195-203

Weidhase RA, Lehmann J, Kramell HM, Sembdner G, Parthier B (1987) Degradation of ribulose-1,5-bisphosphate carboxylase and chlorophyll in senescing barley leaf segments triggered by jasmonic acid methylester, and counteraction by cytokinin. Physiol Plant 69:161-166

Wintermans JFGM, De Mots A (1965) Spectrophotometric characteristics of chlorophyll $\mathrm{a}$, and $\mathrm{b}$, and their pheophytins in ethanol. Biochim Biophys Acta 109:448-453 